\title{
Effect of diet and physical exercise intervention programmes on coronary heart disease risk in smoking and non-smoking men in Sweden
}

\author{
Görel K Näslund, Mats Fredrikson, Mai-Lis Hellénius, Ulf de Faire
}

\begin{abstract}
Study objective - To investigate differences between smokers and non-smokers in health behaviour, cardiovascular risk factors, coronary heart disease (CHD) risks, health knowledge, health attitudes, and compliance with a CHD prevention programme.
\end{abstract}

Design - Differences between smokers and non-smokers were studied via medical examinations, questionnaires, physical exercise activity logs, and food record sheets. Data were analysed using univariate and multivariate analyses. The five and 10 year CHD risks were assessed using the Framingham CHD risk estimate.

Setting - The Karolinska Hospital, Stockholm, and Sollentuna Primary Health Centre, Sollentuna, Sweden.

Participants - The analyses were based on 158 healthy smoking and non-smoking men aged 35-60 years with raised cardiovascular risk factors who enrolled in controlled, randomised six month diet and exercise programmes.

Main results - Discriminant analysis suggested that smokers, compared with nonsmokers, were characterised by a higher alcohol energy percent, lower HDL cholesterol concentration, lower systolic blood pressure, and a higher plasminogen activator inhibitor-1 (PAI-1) value. Knowledge of the risk factors for CHD was not a discriminating factor. Both smokers and non-smokers increased the exercise taken, improved their diet, and lowered their CHD risk. Before, as well as after the intervention, smokers had a higher CHD risk than non-smokers.

Conclusions - The best CHD prevention action that could be taken by smokers would of course be to quit smoking. Those who cannot stop should be encouraged to improve their diet and increase the amount of physical exercise they take in order to reduce the health hazards of their smoking behaviour.

\section{( $\mathcal{F}$ Epidemiol Community Health 1996;50:131-136)}

Numerous studies show differences in the diet of smokers compared with non-smokers. It has been reported that smokers have lower intakes of fibre, vitamin $C$, vitamin $A$, polyunsaturated fat, protein, and carbohydrates. ${ }^{12}$ Smokers have been found to drink more coffee and alcohol, ${ }^{34}$ and to add more salt to their food. ${ }^{56}$ It is possible that smoking influences a person's food preferences by an effect on taste ${ }^{7}$ or that smokers pursue a more "unhealthy" lifestyle than non-smokers. Cockburn, for example, has reported less use of sun protection measures in smokers than in non-smokers. ${ }^{8}$ With regard to physical exercise, data are conflicting. A number of studies show no association between smoking and physical exercise, while some studies show a weak negative relationship or have reported smoking as a characteristic for drop outs in an exercise programme. ${ }^{910}$ Castro et $a l^{11}$ found that moderate to heavy smokers exhibit lower levels of health consciousness and lower commitment to enact healthy behavioural changes than non-smokers and light smokers.

Smoking is associated with a number of physiological changes which increase the CHD risk. Compared with non-smokers, smokers have raised serum concentrations of cholesterol, serum triglycerides, and VLDL triglycerides, and attenuated HDL cholesterol. ${ }^{12-15}$ It has also been suggested that the decreased ingestion of fibre could contribute to the increased risks of $\mathrm{CHD}$ and cancer in smokers. ${ }^{4}$ Furthermore, it has been shown that a diet low in dietary fibre is linked to high plasminogen activator inhibitor-1 (PAI-1) values, thereby impairing the fibrinolytic capacity and adding to the CHD risk. ${ }^{16}$

In this study, we wished to establish the dietary pattern, cardiovascular risk factors, CHD risk, health beliefs, and health knowledge in smoking and non-smoking middle aged men. Because smoking is linked to a different intake of nutrients, ${ }^{2}$ as well as to a low commitment to improve health behaviour, ${ }^{11}$ our aim was to study the result of six month diet and exercise programmes among smokers and non-smokers. The diet and exercise intervention programme has been described previously. Men in the intervention groups significantly reduced a number of risk factors for cardiovascular disease and lowered their estimated CHD risk compared with the control group. Diet and exercise were about equally effective in reducing cardio- 
vascular risk. ${ }^{17}$ The theoretical foundation for the present study was the health belief model ${ }^{18}$ which stresses psychosocial factors as determinants of health behaviour.

\section{Methods \\ SUBJECTS}

A CHD prevention programme which combined a population and individual high risk strategy was started in 1988 in Sollentuna, Greater Stockholm. ${ }^{19}$ All adult visitors to the Sollentuna Primary Health Care Centre who were under 60 years of age were given the opportunity to fill out a short questionnaire on possible CHD risk factors. Those whose questionnaire indicated the presence of one or more risk factors were offered a free check up of physiological risk factors and possible treatment. Between August 1988 and April 1990, 3000 visitors to the Sollentuna Centre (11\% of all visitors in the age group 15-60 years) completed the questionnaire.

Letters with invitations to participate in a randomised, controlled study on the effects of non-pharmacological treatment on CHD risk factors were sent to a consecutive sample of 187 men aged $35-60$ years with slightly to moderately raised cardiovascular risk factors who were newly registered in the prevention programme. Twenty seven men declined to enroll in the programme. Of the 160 men who accepted the invitation, two were excluded due to chronic disease. The inclusion criteria were: no history of CHD, diabetes or other severe chronic disease; no regular intake of pharmacological agents; serum cholesterol 5.2$7.8 \mathrm{mmol} / 1$; serum triglycerides $<5.6 \mathrm{mmol} / 1$; fasting blood glucose $<6.7 \mathrm{mmol} / 1$; and diastolic blood pressure $<100 \mathrm{mmHg}$ (measured after five minutes' rest in the supine position). The subjects joined the study from May to December 1990, and were re-examined from December 1990 to May 1991.

Twenty six per cent of the subjects were regular smokers, and this corresponded to the proportion of regular smokers among Swedes older than 16 years of age. ${ }^{20}$ Fifty per cent of the smokers were light smokers (mean 4 cigarettes per day; range 1 to 10 cigarettes). Thirty per cent were moderate smokers (mean 16 cigarettes; range 11 to 20 cigarettes), and 20 per cent were heavy smokers (mean 30 cigarettes; range 21 to 40 cigarettes). Of the non-smokers, $38 \%$ were ex-smokers.

\section{CARDIOVASCULAR RISK FACTORS}

Body weight

Body weight was measured to the nearest $0 \cdot 1 \mathrm{~kg}$ by the same nurse using a calibrated electronic weighing device (Seca delta model 707). Body mass index (BMI) was calculated as body weight in $\mathrm{kg}$ divided by height in $\mathrm{m}^{2}$.

\section{Blood pressure}

Blood pressure was determined to the nearest $2 \mathrm{mmHg}$ by the same physician, with the patient supine after five minutes' rest, and using a standard auscultatory method with a $12 \times 35 \mathrm{~cm}^{2}$ cuff. The systolic blood pressure (SBP) was noted at the appearance of Korotkoff sounds, and the diastolic blood pressure (DBP) at the disappearance of the sounds. Both SBP and DBP were calculated as the mean value of two determinations.

\section{Lipoproteins and apolipoproteins}

Venous blood samples were drawn from an antecubital vein after overnight fasting and with recommendations on the avoidance of strenuous physical activities during the preceding 24 hours. Serum was prepared by centrifugation at $3000 \mathrm{rpm}$ and it was stored at $-70^{\circ} \mathrm{C}$ until all the samples could be analysed at the end of the study. Since all samples could not be assayed in the same run, care was taken to include both samples from each individual in the same batch to maximise the analytical precision. The major serum lipoproteins (VLDL, LDL, and HDL cholesterol) were determined from fresh serum samples by preparative ultracentrifugation, precipitation and quantitative lipid analysis. ${ }^{21}$ Apolipoprotein A (Apo A) and apolipoprotein B (Apo B) were determined using turbidity immunoassay methods (Roche, Basel, Switzerland).

\section{PAI-1}

PAI-1 activity was determined by adding a certain amount of tissue-type plasminogen activator ( $t-P A)$ to diluted plasma and measuring residual t-PA activity. ${ }^{22}$ The results were expressed in arbitrary units, one unit corresponding to the amount that inhibited one international unit of t-PA (calibrated with reference preparation $83 / 517$ for t-PA, National Institute for Biological Standards and Control, London, UK).

\section{THE HEALTH BELIEF QUESTIONNAIRE}

A questionnaire on health beliefs and health knowledge based on a protocol developed by Näslund $e t a^{23}$ was used. The first section of this health belief questionnaire included Likert scale items on the person's interest in nutrition, belief in a link between food and health, belief in diet and physical activity as preventive measures against CHD (perception of benefits), fear of becoming a CHD victim (perception of susceptibility), and perception of the consequences of stroke and myocardial infarction (perception of severity).

The second section covered health knowledge which was assessed by using a matrix of seven health problems (diabetes, heart disease, lung cancer, mental illness, high blood pressure, raised blood lipids, and skin cancer) and nine potentially related factors (smoking, alcohol, physical exercise, stress, heredity, animal fat, salt, dietary fibre, sunbathing). Subjects were asked to mark the appropriate box if they thought that the health problem was influenced by a certain factor. A score on health knowledge was computed by summing the correct answers 
on which factors are associated to heart disease, high blood pressure, and high blood lipids.

The beliefs in the importance of 16 health related behaviours, including CHD preventive behaviours such as not to smoke, eating fibre, avoiding dietary fat, avoiding excess coffee, avoiding excess sugar, taking regular exercise, avoiding stress, and having yearly blood pressure measurements, were assessed on 10 point scales.

\section{PROCEDURE}

At baseline, and after the intervention, all subjects underwent a medical examination which included measures of height, weight, blood pressure, blood sampling, a physical exercise test on a bicycle ergonometer, and a glucose tolerance test. Relative weight was estimated with BMI. The five and 10 year CHD risks were estimated at baseline and after the intervention using the Framingham CHD risk estimate. It is based on the combined impacts of age, cigarette smoking, total and HDL cholesterol, systolic blood pressure, diabetes mellitus, and left ventricular hypertrophy. ${ }^{24}$

The subjects were given the health belief questionnaire to be completed at the hospital in connection with the baseline medical examination. After a standardised interview including family situation, occupation, smoking habits, family history of CHD and diabetes, and exercise habits, the men were randomised to a diet group (D, $n=40)$, exercise group (E, $\mathrm{n}=39$ ), diet and exercise group ( $\mathrm{DE}, \mathrm{n}=39$ ), and a control group $(C, n=40)$. Stopping smoking was neither encouraged nor discouraged by the test leaders.

\section{Diet intervention}

Subjects in the $\mathrm{D}$ and $\mathrm{DE}$ groups were given individual verbal and written dietary advice by the physician at baseline. Two weeks later the men and their wives/partners, if present, met a dietician who gave further individual dietary advice. The dietary recommendations were in accordance with the National Cholesterol Education Program Step $1^{25}$ and other consensus documents. ${ }^{26-28}$ The advice included energy intake to reach or maintain desirable weight, total fat $<30$ energy percent $(\mathrm{E} \%)$, carbohydrates (mainly complex) 50-60 E\%, and cholesterol $<300 \mathrm{mg} /$ day.

At baseline, and the week before the follow up examination, the men in all groups completed a precoded seven day food record sheet with preprinted alternatives for foods consumed at meals. The sizes of cooked food portions were estimated using a portion guide, and spreads on bread were estimated based on a photograph. Foods consumed between meals were also recorded. The total daily energy intake and intake of nutrients were assessed from the food record sheet and calculated with a computer program. ${ }^{29}$

\section{Physical activity}

Subjects randomised to $\mathrm{E}$ and $\mathrm{DE}$ groups were given individual verbal and written information on exercise by the physician. Regular exercise of an aerobic type (for example, walking and jogging) taken two to three times a week at an intensity of $60-80 \%$ of maximal heart rate, and lasting 30-45 minutes was recommended. ${ }^{30}$ The men were told to maintain activity logs specifying the date, type of activity, duration, and intensity ${ }^{31}$ of each exercise session. In addition, they were given the opportunity to engage in aerobic sessions two to three times per week.

ETHICS

The study conformed to the principles embodied by the Declaration of Helsinki and was approved of by the ethics committee at the Karolinska Hospital, Stockholm.

\section{COMPLIANCE}

All subjects, except for one man in the control group, returned for the follow up examination after six months. All subjects completed the health belief questionnaire. Data on the intake of energy and nutrients calculated from the food record sheet completed at baseline and the week before the follow up examination after six months served as measures of dietary habits. Twenty eight men did not hand in completed food record sheets. The activity logs maintained by the subjects in $\mathrm{E}$ and $\mathrm{DE}$ groups during the intervention were used as a measure of compliance with increased physical exercise according to given recommendations. In addition, the physician undertook a standardised interview with the men at baseline and after six months asking questions about the frequency of exercise sessions, type of activity, duration, and intensity.

\section{STATISTICS}

Data were analysed using discriminant analysis, Student's $t$ test, and $\chi^{2}$ statistics. Post hoc tests included Fisher PLSD and Tukey's HSD. A $95 \%$ confidence interval was chosen as a measure of uncertainty for estimates of within group changes in dietary factors and CHD risks.

\section{Results}

Student's $t$ test showed no differences between ex-smokers and never smokers with regard to dietary pattern and cardiovascular risk factors. Because of this, the two groups have been considered together as non-smokers in the subsequent analyses.

\section{BACKGROUND CHARACTERISTICS}

The $\chi^{2}$ statistic showed that when smokers were compared with non-smokers the former were more likely to be blue collar workers $(43.1 \%$ versus $20.6 \%$ workers; $p<0 \cdot 01$ ). Smokers and non-smokers were similar in terms of marital status. Student's $t$ test showed that the groups were similar in age (mean age 46 years, range 35-60). 
Table 1 Diet of smokers and non-smokers at baseline. $p$ values for differences between smokers and non-smokers based on Student's t tests

\begin{tabular}{lcll}
\hline & $\begin{array}{c}\text { Smokers } \\
(n=30)\end{array}$ & $\begin{array}{l}\text { Non-smokers } \\
(n=100)\end{array}$ & $p$ value \\
\hline Energy (kJ/d) & 8789 & 8770 & 0.97 \\
Total fat (E\%) & 36.6 & 35.7 & 0.43 \\
Polyunsaturated fat & 5.7 & 5.5 & 0.49 \\
(E\%) & $16 \cdot 1$ & 18.2 & 0.04 \\
Fibre (g/d) & 42.4 & 45.5 & 0.007 \\
Carbohydrates (E\%) & 4.4 & 6.7 & 0.83 \\
Saccharose (E\%) & 6.8 & 14.0 & 0.82 \\
Protein (E\%) & 14.1 & 1.9 & 0.91 \\
$\beta$ carotene (mg/d) & 1.9 & 64.5 & 0.26 \\
Vitamin C (mg/d) & $57 \cdot 2$ & 7.0 & 0.87 \\
Vitamin E (mg/d) & $7 \cdot 1$ & 4.9 & 0.004 \\
Alcohol (E\%) & $7 \cdot 2$ & 4.9 & \\
\hline
\end{tabular}

Table 2 Cardiovascular risk factors of smokers and nonsmokers at baseline. $p$ values for differences between smokers and non-smokers based on Student's t tests

\begin{tabular}{|c|c|c|c|}
\hline & $\begin{array}{l}\text { Smokers } \\
(n=41)\end{array}$ & $\begin{array}{l}\text { Non-smokers } \\
(n=117)\end{array}$ & $p$ value \\
\hline Body mass index & $25 \cdot 6$ & $25 \cdot 1$ & $0 \cdot 38$ \\
\hline $\begin{array}{l}\text { Systolic blood pressure } \\
\text { (mmHg) }\end{array}$ & $126 \cdot 0$ & $131 \cdot 8$ & 0.03 \\
\hline $\begin{array}{l}\text { Diastolic blood } \\
\text { pressure }(\mathrm{mmHg})\end{array}$ & $80 \cdot 7$ & $81 \cdot 7$ & 0.51 \\
\hline $\begin{array}{l}\text { Serum cholesterol } \\
(\mathrm{mmol} / \mathrm{l})\end{array}$ & $6 \cdot 0$ & $6 \cdot 2$ & $0 \cdot 41$ \\
\hline $\begin{array}{l}\text { HDL cholesterol } \\
(\mathrm{mmol} / \mathrm{l})\end{array}$ & $1 \cdot 2$ & $1 \cdot 4$ & $0 \cdot 002$ \\
\hline $\begin{array}{l}\text { Serum triglycerides } \\
(\mathrm{mmol} / \mathrm{l})\end{array}$ & $1 \cdot 7$ & $1 \cdot 3$ & 0.01 \\
\hline $\begin{array}{l}\text { VLDL triglycerides } \\
(\mathrm{mmol} / \mathrm{l})\end{array}$ & $1 \cdot 1$ & 0.08 & $0 \cdot 02$ \\
\hline PAI-1 (U/ml) & $15 \cdot 4$ & $10 \cdot 9$ & 0.03 \\
\hline Apo A (g/l) & $1 \cdot 4$ & $1 \cdot 5$ & 0.004 \\
\hline
\end{tabular}

PAI-1 = plasminogen activator inhibitor-1; Apo $A=$ apolipoprotein $\mathrm{A} ; \mathrm{HDL}=$ high density lipoprotein; $\mathrm{VLDL}=$ very low density lipoprotein.

\section{HEALTH BELIEFS}

The $\chi^{2}$ statistic showed no differences between smokers and non-smokers with regard to interest in nutrition, belief in a link between food and health, belief in diet and physical activity as CHD preventive actions, perceptions of severity of illness, and susceptibility to illness.

\section{HEALTH BEHAVIOUR}

The dietary pattern of all smokers and nonsmokers $(n=130)$ at baseline is presented in table 1. Data from 28 men are missing because of incomplete food record sheets. Student's $t$ test showed that the diet of smokers, compared with non-smokers, was characterised by a lower intake of fibre, a lower carbohydrate $\mathrm{E} \%$, and a higher alcohol E\%. Smokers and non-smokers engaged in a similar number of physical exercise sessions per month ( $4 \cdot 5$ and $5 \cdot 6$, respectively).

\section{CARDIOVASCULAR RISK FACTORS}

Data on cardiovascular risk factors for all smokers and non-smokers $(n=158)$ at baseline are presented in table 2 . Student's $t$ test showed that smokers had lower levels of HDL cholesterol and Apo A, lower SBP, and higher levels of serum triglycerides, VLDL triglycerides, and PAI-1 than non-smokers. No subjects had diabetes mellitus or left ventricular hypertrophy.
Table 3 Variables significantly discriminating between smokers and non-smokers in stepwise discriminant analysis $(n=130)$

\begin{tabular}{lll}
\hline & $F$ value $^{*}$ & $p$ value \\
\hline $\begin{array}{l}\text { Subgroup: dietary variables } \\
\text { Alcohol (E\%) }\end{array}$ & 6.5 & $<0.001$ \\
$\begin{array}{l}\text { Subgroup: cardiovascular risk } \\
\text { factors }\end{array}$ & & \\
HDL & 5.3 & $<0.01$ \\
SBP & 6.9 & $<0.001$ \\
PAI-1 & 5.6 & $<0.001$ \\
Subgroup: knowledge and & & \\
attitudes & & \\
Attitude to smoking & 27.6 & $<0.001$ \\
\hline
\end{tabular}

* $\mathrm{F}$ values indicated in the tables are the $\mathrm{F}$ values when all selected variables had been entered in the equation ( $F$ to remove).

\section{Discriminant analysis}

To discriminate between smokers and nonsmokers, three separate stepwise discriminant analyses were performed. The variable with the highest F-value was entered at each step as long as a substantial contribution to the discriminating function could be found, $F>4$. The results are presented in table 3 . The alcohol $\mathrm{E} \%$ was found to discriminate between smokers and non-smokers in the stepwise discriminant analysis in which dietary variables were entered. HDL cholesterol, SBP, and PAI-1 were the physiological variables found to discriminate between smokers and non-smokers. A third discriminant analysis was performed using the score on health knowledge and the ratings on the importance of different positive health practices. Attitude to smoking was found to be the only discriminating variable. Thus, the discriminant analyses suggested that smokers were characterised by a higher alcohol $\mathrm{E} \%$, lower HDL cholesterol level, lower SBP, higher PAI1 level, and a more favourable attitude to smoking than non-smokers.

\section{DIETARY CHANGES}

Table 4 presents the dietary changes made by smokers and non-smokers in the D and DE groups during the intervention. Men in the $\mathrm{E}$ and $\mathrm{C}$ group were not told to change their diet, and are therefore not included. Both smokers and non-smokers significantly increased their intake of fibre, carbohydrate $\mathrm{E} \%$, betacarotene, and protein $\mathrm{E} \%$. Smokers and non-smokers also decreased the fat $\mathrm{E} \%$. Smokers significantly increased their intake of vitamin $\mathrm{C}$ and reduced the saccharose $\mathrm{E} \%$, while nonsmokers decreased energy intake and polyunsaturated fat $\mathrm{E} \%$ and alcohol $\mathrm{E} \%$.

\section{CHANGES IN SMOKING BEHAVIOUR}

One man in the diet and exercise group stopped smoking and one man in the exercise group started smoking during the intervention programme.

\section{CHANGES IN PHYSICAL EXERCISE}

Both smokers and non-smokers in $\mathrm{E}$ and DE groups increased physical exercise. The two 
Table 4 Differences in dietary intake after six months of intervention among men in the diet and dietlexercise groups. Mean (95\% confidence intervals*). No differences between smokers and non-smokers were found.

\begin{tabular}{llc}
\hline & $\begin{array}{l}\text { Smokers } \\
(n=20)\end{array}$ & $\begin{array}{l}\text { Non-smokers } \\
(n=45)\end{array}$ \\
\hline Energy (kJ) & $-717(-1504,70)$ & $-597(-1152,-43)$ \\
Fat (E\%) & $-3 \cdot 8(-6 \cdot 5,-1 \cdot 1)$ & $-2 \cdot 8(-4 \cdot 4,-1 \cdot 32)$ \\
Polyunsaturated fat (E\%) & $-0 \cdot 5(-1 \cdot 2,0 \cdot 2)$ & $-0 \cdot 5(-1 \cdot 04,-0 \cdot 02)$ \\
Fibre (g/d) & $3 \cdot 1(0 \cdot 9,5 \cdot 3)$ & $1 \cdot 8(0 \cdot 6,3 \cdot 1)$ \\
Carbohydrates (E\%) & $4 \cdot 0(0 \cdot 5,7 \cdot 4)$ & $2 \cdot 0(0 \cdot 4,3 \cdot 6)$ \\
Saccharose (E\%) & $-2 \cdot 4(-3 \cdot 8,-0 \cdot 9)$ & $-0 \cdot 9(-1 \cdot 9,0 \cdot 1)$ \\
Protein (E\%) & $1 \cdot 6(0 \cdot 5,2 \cdot 7)$ & $1 \cdot 5(0 \cdot 8,2 \cdot 1)$ \\
$\beta$ carotene (mg/d) & $1 \cdot 3(0 \cdot 4,2 \cdot 3)$ & $1 \cdot 2(0 \cdot 5,1 \cdot 9)$ \\
Vitamin C (mg/d) & $23 \cdot 9(8 \cdot 0,39 \cdot 9)$ & $5 \cdot 2(-6 \cdot 2,16 \cdot 6)$ \\
Vitamin E (mg/d) & $-1 \cdot 0(-2 \cdot 2,0 \cdot 2)$ & $-0.7(-1 \cdot 5,0 \cdot 9)$ \\
Alcohol (E\%) & $-2 \cdot 1(-4 \cdot 4,0 \cdot 2)$ & $-0 \cdot 8(-1 \cdot 4,-0 \cdot 1)$ \\
\hline
\end{tabular}

*A confidence interval which does not include zero indicates a significant change within the group.

Table 5 Estimated five and 10 year coronary heart disease (CHD) risks (\% CHD events during five and 10 years, respectively) for smokers and non-smokers in intervention groups. Mean (95\% confidence intervals). p values for between group comparisons based on Student's t test.

\begin{tabular}{lccc}
\hline & $\begin{array}{l}\text { Smokers } \\
(n=32)\end{array}$ & $\begin{array}{l}\text { Non-smokers } \\
(n=86)\end{array}$ & $p$ value \\
\hline $\begin{array}{l}\text { At } 5 y \\
\text { CHD risk at baseline }\end{array}$ & $4 \cdot 4$ & 3.2 & 0.003 \\
$\begin{array}{l}\text { CHD risk after } \\
\text { intervention }\end{array}$ & 3.9 & $2 \cdot 7$ & 0.008 \\
$\begin{array}{l}\text { Mean change in CHD } \\
\text { risk }\end{array}$ & $-0.66(-1 \cdot 16,-0 \cdot 15)$ & $-0.44(-0.75,-0 \cdot 14)$ & 0.47 \\
$\begin{array}{l}\text { At 10y } \\
\text { CHD risk at baseline }\end{array}$ & 9.9 & & \\
$\begin{array}{l}\text { CHD risk after } \\
\text { intervention }\end{array}$ & 8.8 & 7.2 & 0.002 \\
$\begin{array}{l}\text { Mean change in CHD } \\
\text { risk }\end{array}$ & $-1.10(-2.05,-0.14)$ & $-1.0(-1.56,-0.46)$ & 0.89 \\
\hline
\end{tabular}

* A confidence interval which does not include zero indicates a significant change within the groups.

groups engaged in a similar number of exercise sessions after intervention $(9 \cdot 0$ and 11.4 sessions per month, respectively).

\section{CHD RISK}

Table 5 presents the estimated CHD risk of smokers and non-smokers in the intervention groups $(n=118)$ at baseline and after intervention, and mean changes. Smokers had significantly higher estimated five year and 10 year CHD risk before, as well as after, intervention compared with non-smokers. Both smokers and non-smokers lowered their five and 10 year $\mathrm{CHD}$ risks during the intervention period. A Framingham risk estimate showed that if the smokers would quit smoking, their five and 10 year CHD risks after intervention would be reduced to $2 \cdot 8$ and $6 \cdot 7 \%$, respectively, or similar to the risks of the non-smoking group.

\section{Discussion}

Discriminant analyses showed that smokers were characterised by a significantly higher alcohol E\%, lower level of HDL cholesterol, lower SBP, and a higher level of PAI-1 compared with non-smokers. The higher alcohol intake in smokers is well documented. ${ }^{3} \mathrm{~A}$ moderate alcohol intake, compared with a lower intake, is associated with increased HDL cholesterol. ${ }^{32}$ A possible explanation for the lower HDL cholesterol concentration in the smokers despite the higher alcohol consumption may be that the negative effect of smoking on HDL cholesterol is stronger than the positive effect of alcohol. Previous studies have also reported lower HDL cholesterol in smokers. ${ }^{12}$ With regard to SBP, results from epidemiological studies have generally shown that smokers have lower blood pressure than non-smokers. ${ }^{33}$

It has previously been reported that smokers have lower intakes of fibre, vitamin $\mathrm{C}$, vitamin $A$, polyunsaturated fat, protein, and carbohydrates, ${ }^{12}$ as well as higher concentrations of serum cholesterol, serum triglycerides, and VLDL triglycerides. ${ }^{12-15}$ Student's $t$ test showed a lower intake of fibre and carbohydrates, as well as higher serum triglycerides, VLDL triglycerides, and Apo A among smokers, but this was not confirmed in the discriminant analysis. It cannot be excluded that the lack of difference in this study between smokers and non-smokers with regard to dietary and physiological factors could be due to a type II error because of the small number of smokers.

Both smokers and non-smokers increased the amount of physical exercise they took and managed a number of positive dietary changes during the intervention. For example, both groups increased their intake of dietary fibre and $\beta$ carotene. The subjects were advised to lower their fat intake to $30 \mathrm{E} \%$. Neither the smoking nor the non-smoking group managed this reduction but both made a significant reduction in fat $\mathrm{E} \%$ consumption. With respect to vitamin $\mathrm{C}$, only smokers ate significantly more.

It is interesting that smokers and nonsmokers reported the same belief in a link between diet and health, and had similar beliefs in diet and physical exercise as preventive health actions. Despite having a higher CHD risk, smokers perceived that they had the same susceptibility to stroke and myocardial infarction as non-smokers. This cannot easily be explained by lack of knowledge, since knowledge of risk factors for cardiovascular disease, including the hazards of smoking, was not different in smokers and non-smokers. It is possible that smokers systematically underestimate the CHD risk associated with smoking. With regard to attitudes towards positive health practices, the discriminant analysis showed that smokers and non-smokers shared similar attitudes except that smokers had a more favourable attitude towards smoking.

Both smokers and non-smokers lowered their five and 10 year CHD risks by effecting changes in cardiovascular risk factors due to the diet and physical exercise programme. ${ }^{17}$ However, both initially and after the intervention, smokers were characterised by a higher CHD risk than non-smokers. The most important behavioural change for smokers would be to quit smoking. Stopping smoking would not only lower the estimated CHD risk but possibly also reduce the impact of risk mechanisms such as oxidative damage. ${ }^{2}$ Furthermore, stopping smoking may change and improve the diet of the smokers. It has been reported that after a few years, the diet of ex-smokers is similar to that of never smokers. ${ }^{3435}$ Quitters also tend to have an improved health consciousness. ${ }^{36}$ In 
this study, ex-smokers and never smokers were similar both in respect of dietary factors and cardiovascular risk factors. This result suggests that to manage smoking cessation among middle aged men, an approach aimed at changes of attitude towards smoking may be more effective than an intervention aiming at improved health knowledge.

It is concluded that both smoking and nonsmoking middle aged men may improve their diet and exercise pattern during a six month intervention programme and thus lower their $\mathrm{CHD}$ risk. However, the best $\mathrm{CHD}$ preventive measure for smokers is to quit smoking. Smokers who will not quit smoking should be persuaded to improve their eating habits with regard to dietary fibre ${ }^{16}$ and antioxidants, ${ }^{2}$ and to increase the amount of physical exercise they take in order to reduce the health injurious impact of their smoking behaviour.

This study was supported by funds from the Bank of Sweden Tercentenary Foundation and the Swedish Lung-Heart Foundation.

1 Fehily AM, Phillips KM, Yarnell JWG. Diet, smoking, social class and body mass index in the Caerphilly heart disease study. Am F Clin Nutr 1984;40:827-33.

2 Margetts BM, Jackson AA. Interactions between people's diet and their smoking habits: the dietary and nutritional diet and their smoking habits: the dietary and nut
survey of British adults. BMF 1993;307:1381-4.

3 Wichelow MJ, Erzinclioglu SW, Cox BD. A comparison of the diets of non-smokers and smokers. Br f Addict 1991; 86:71-81.

4 Midgette AS, Baron JA, Rohan TE. Do cigarette smokers have diets that increase their risks of coronary heart disease and cancer? Am $\mathcal{F}$ Epidemiol 1993;137:521-9.

5 Fulton M, Thomson M, Elton RA, Brown S, Wood DA, Oliver MF. Cigarette smoking, social class and nutrien intake: relevance to coronary heart disease. Eur $\mathcal{f}$ Clin Nutr 1988;42:797-803.

6 Hostmark AT, Berg J, Brudal S, Berge R, Kierulf P, Bjerkeda $\mathrm{T}$. Coronary risk factors in middle-aged men as related to smoking, coffee intake and physical activity. Scand $\mathcal{F} S o c$ Med 1992;20:196-203.

7 Grunberg NE. The effects of nicotine and cigarette smoking on food consumption and taste preferences. Addict Behav 1982;7:317-31.

8 Cockburn J, Hennrikus D, Scott R, Sanson-Fisher R. Adolescent use of sun-protection measures. Med f Aust 1989 151:136-40.

9 Oldridge MB. Compliance of post myocardial infarction patients to exercise programs. Med Sci Sports 1979;11: 373-5.

10 Blair SN, Jacobs DR, Powell KE. Relationship between exercise or physical activity and other health behaviors. Public Health Rep 1985;100:172-80.

11 Castro FG, Newcomb MD, McCreary C, Baezconde-Garbanati L. Cigarette smokers do more than just smoke cigarettes. Health Psychol 1989;8:107-29.

12 Craig WY, Palomaki GE, Haddow JE. Cigarette smoking and serum lipid and lipoprotein concentrations: an analysis of published data. BMY 1989;298:784-8.

13 Williams A, Robinson D, Bailey A. High density lipoprotein and coronary risk factors in normal men. Lancet 1979; 72-5.
14 Willett W, Hennekens CH, Castell W, Rossner B, Evans D, Taylor J, Kass EH. Effects of cigarette smoking on fasting triglyceride, total cholesterol and high density lipoprotein in women. Am Heart $\mathcal{F} 1983 ; 105: 417-21$.

15 Freedman DS, Srinivasan SR, Shear CL, Hunter SM, Crof JB, Webber LS, Berenson GS. Cigarette smoking initiation and longitudinal changes in serum lipids and lipoprotein in early adulthood: the Bogalusa heart study. $A m \mathcal{F} E p-$ idemiol 1983;124:207-19.

16 Nilsson TK, Sundell I, Hellsten G, Hallmans G. Reduced plasminogen activator inhibitor activity in high consumers of fruits, vegetables and root vegetables. $\mathcal{F}$ Intern $\mathrm{Med}$ 1990;227:267-71.

17 Hellenius ML, de Faire U, Berglund B, Hamsten A, Krakau I. Diet and exercise are equally effective in reducing risk for cardiovascular disease. Results of a randomized risk for cardiovascular disease. Results of a randomized, controlled study of men with slightly to moderately raised

18 Becker MH, Rosenstock IM. Compliance with medical advice. In: Steptoe A, Mathews A, eds. Health care and human behaviour. London: Academic Press, 1984:180-3.

19 Hellenius ML, de Faire U, Krakau I, Berglund B. Prevention of cardiovascular disease within the primary health care system - feasibility of a prevention programme within the Sollentuna primary health care catchment area. Scand $\mathcal{F}$ Prim Health Care 1993;11:68-73.

20 Socialstyrelsen. Folkhälsorapport 1991 (public health report; in Swedish). Stockholm: Socialstyrelsen, 1992:168.

21 Carlson K. Lipoprotein fractionation. 7 Clin Pathol 1973; 26:32.

22 Chiemelewska J, Rånby $M$, Wiman B. Evidence for a rapid inhibitor to tissue plasminogen activator in plasma. Thromb Res 1983;31:427-36.

23 Näslund GK, Wardle J, Steptoe A, Fredrikson M. Health behavior, knowledge and attitudes among Swedish university students. Scand F Psychol 1993;34:197-211.

24 Anderson KM, Wilson PWF, Odell PM, Kannel WB. An updated coronary risk profile. AHA Statement. Circulation 1991;83:356-62.

25 Expert Panel of the National Cholesterol Education Program. Report of the National Cholesterol Education Program Expert Panel on detection, evaluation, and treatment of high blood cholesterol in adults. Arch Intern Med 1988; 148:36-69.

26 Grundy SM, Arky R, Bray GA, et al. Coronary risk factor statement for the American public. A statement of the
Nutrition Committee, American Heart Association. CirNutrition Committee, Am
culation 1985;72:1135-9.

27 European Atherosclerosis Study Group. Strategies for the prevention of coronary heart disease: a policy statement of the European Atherosclerosis Society. Eur Heart $\mathcal{F} 1987$ 8:77-88.

28 WHO Study Group. Diet, nutrition and the prevention of chronic diseases. WHO Technical Report Series 797. Geneva: World Health Organization, 1990.

29 Becker W. The Swedish household survey 1989. Presented at the Sixth European Nutrition Conference, Athens, Greece. (Abstract) in Nutritional science, new development of consumer concern, 1991.

30 Gordon NF, Scott CB, Wilkinson WJ, Duncan JJ, Blair SN. Exercise and mild essential hypertension. Recommendations for adults. Sports Med 1990;10:390-404.

31 Borg G. Perceived exertion as an indicator of somatic stress. Scand 7 Rehab Med 1970;23:92-6.

32 Gaziano JM, Buring JE, Breslow JL, et al. Moderate alcohol intake, increased levels of high-density lipoprotein and its subfractions, and decreased risk of myocardial infarction. $N$ Engl f Med 1993;329:1829-34.

33 Green MS, Jucha E, Luz Y. Blood pressure in smokers and nonsmokers: epidemiological findings. Am Heart $\mathcal{F} 1986$; 111:932-40.

34 Morabia A, Wynder EL. Dietary habits of smokers, people who never smoked and ex-smokers. Am f Clin Nutr 1990; 52:933-7.

35 Bolton-Smith C, Woodward M, Brown CA, Tunstall-Pedoe H. Nutrient intake by duration of ex-smoking in the
Scottish heart health study. Br $\mathcal{F}$ Nutr 1993;69:315-32.

36 West DW, Graham S, Swanson M, Wilkinson G. Five year follow-up of a smoking withdrawal clinic population. $A m$ f Public Health 1977;67:536-44. 